\title{
土の降伏条件に関する一試案とその考察
}

\section{A PROPOSAL OF NEW YIELD CRITERION FOR SOILS}

\section{1. まえがき}

土の降伏条件については，古くから多くの研究者に よって実験や理論による研究がなされてきた ${ }^{1)}$ 。現在考 えられている降伏条件式を，簡単のため粘着力のない場 合についてあげれば，次の三つである。

(a) Mohr-Coulomb の条件

$$
\begin{gathered}
\max \left(\frac{\left|\sigma_{1}-\sigma_{2}\right|}{\sigma_{1}+\sigma_{2}}, \frac{\left|\sigma_{2}-\sigma_{3}\right|}{\sigma_{2}+\sigma_{3}}, \frac{\left|\sigma_{3}-\sigma_{1}\right|}{\sigma_{3}+\sigma_{1}}\right) \\
\quad=k_{a}\left(=\sin \varphi_{a}\right) \ldots \ldots \ldots \ldots \ldots \ldots \ldots \ldots \ldots \ldots \ldots \ldots \ldots \ldots \ldots \ldots
\end{gathered}
$$

または, $\sigma_{1} \geq \sigma_{2} \geq \sigma_{3}$ として

$$
\frac{\sigma_{1}-\sigma_{3}}{\sigma_{1}+\sigma_{3}}=k_{a}
$$

(b) 拡張 Tresca の条件

$$
\begin{gathered}
\max \left(\frac{\left|\sigma_{1}-\sigma_{2}\right|}{\sigma_{1}+\sigma_{2}+\sigma_{3}}, \frac{\left|\sigma_{2}-\sigma_{3}\right|}{\sigma_{1}+\sigma_{2}+\sigma_{3}}, \frac{\left|\sigma_{3}-\sigma_{1}\right|}{\sigma_{1}+\sigma_{2}+\sigma_{3}}\right) \\
\quad=k_{b}\left(=\frac{2}{3} \sin \varphi_{b}\right) \ldots \ldots \ldots \ldots \ldots \ldots \ldots \ldots \ldots \ldots \ldots \ldots \ldots \ldots \ldots \ldots \ldots
\end{gathered}
$$

または, $\sigma_{1} \geq \sigma_{2} \geq \sigma_{3}$ として

$$
\frac{\sigma_{1}-\sigma_{3}}{\sigma_{1}+\sigma_{2}+\sigma_{3}}=k_{b}
$$

(c) 拡張 von Mises の条件

$$
\begin{aligned}
& \frac{\sqrt{\left(\sigma_{1}-\sigma_{2}\right)^{2}+\left(\sigma_{2}-\sigma_{3}\right)^{2}+\left(\sigma_{3}-\sigma_{1}\right)^{2}}}{\sigma_{1}+\sigma_{2}+\sigma_{3}} \\
& =k_{c}\left(=\frac{2}{3} \sqrt{2} \sin \varphi_{c}\right)
\end{aligned}
$$

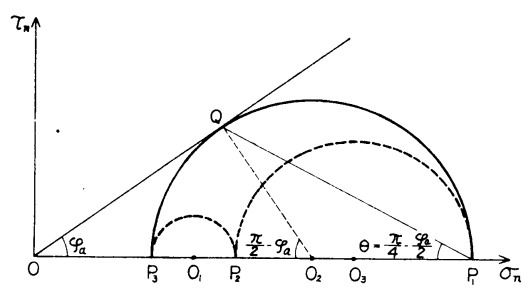

図-1
佐 武 正 雄* By Masao Satake
ここに， $\sigma_{1}, \sigma_{2}, \sigma_{3}$ は三つの主応力で圧縮を正とし， $k_{a}, \varphi_{a}$ 等は材料固有の定数とする。

(a) の条件は，周知のように $\sigma_{n}-\tau_{n}$ 平面に三つの応 力円を画き (図一1， $\overline{O P}_{1}=\sigma_{1}, \overline{O P}_{2}=\sigma_{2}, \overline{O P}_{3}=\sigma_{3}$ ), そ の最外側の（最大半径の）円に原点から接線を引き，そ の傾き $\varphi$ が限界值 $\varphi_{a}$ に達したとき降伏が起こるとす るものであり,これは

$$
\max \frac{\tau_{n}}{\sigma_{n}}=\tan \varphi
$$

によって示される最大の摩擦係数が，限界值 $\tan \varphi_{a}$ に 達するとすべりが生じ降伏が起こるという Coulomb の 法則に基づいている（図一1 とおいて限界の $\tau_{n} / \sigma_{n}$ は $Q$ 点に対応し,すべり面は主軸 I と $\theta= \pm\left(\frac{\pi}{4}-\frac{\varphi_{a}}{2}\right)$ の 角度となすとされている)。(b) の条件は，図一2 にお いて

$$
\overline{O O^{\prime}}=\frac{\sigma_{1}+\sigma_{2}+\sigma_{3}}{3}
$$

とし $\left(O^{\prime}\right.$ は $\overline{P_{i} O_{i}}$ を $2: 1$ に内分する $), \overline{O O_{2}{ }^{\prime}}=\overline{O^{\prime} O_{2}}$ となるようにとった $O_{2}{ }^{\prime}$ 点から，(a) の場合と同様,円 $\mathrm{O}_{2}$ に引いた接線の傾き $\varphi_{2}$ が限界值 $\varphi_{b}$ に達すると降 伏が起こるとするものである。また，(c) の条件は，同 様に $\overline{O O_{i}{ }^{\prime}}=\overline{O^{\prime} O_{i}}$ として, $O_{i}{ }^{\prime}$ 点加ら円 $O_{i}$ に引いた 三つの接線の傾き $\varphi_{i}$ について

$$
\sin ^{2} \varphi_{1}+\sin ^{2} \varphi_{2}+\sin ^{2} \varphi_{3}=2 \sin ^{2} \varphi_{c}
$$

を降伏条件とするものである。注目すべきことは，(a) では中間主応力の影響が無視されているが，(b)，(c) に おいてはこれが加味され，さらに（c) の条件式は応力テ

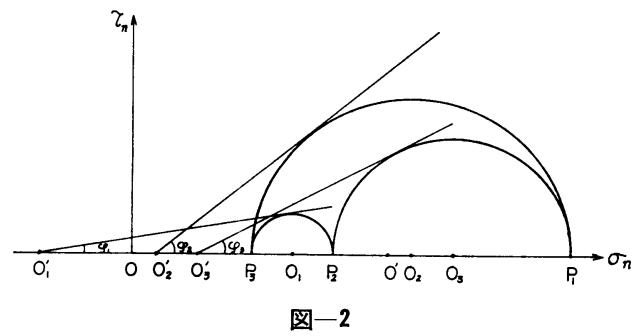

* 正会員 工博 東北大学教授 工学部土木工学科 
ンソルの不変量についての簡単な表現となっていること である (2. で説明)。

以上の 3 条件を主応力 $\sigma_{1}, \sigma_{2}, \sigma_{3}$ を座標軸とする 3 次 元空間で考察すれば，降伏条件を表わす降伏曲面は, い ずれも

$$
\sigma_{1}=\sigma_{2}=\sigma_{3}
$$

で示される直線 $\rho$ を軸線とし，原点を頂点とする錐面 で，(a)，(b) は 6 角錐，(c) は円錐となる。 0 に直交す る平面 $\pi$ は $p$ をパラメーターとして

$$
\sigma_{1}+\sigma_{2}+\sigma_{3}=3 p
$$

と示され，上記 3 錐面の $\pi$ による截り口は 図一 3 に示す 上うに, (a) 正 3 角形に近い 6 角形, (b) 正 6 角形, (c) 円となっている*。

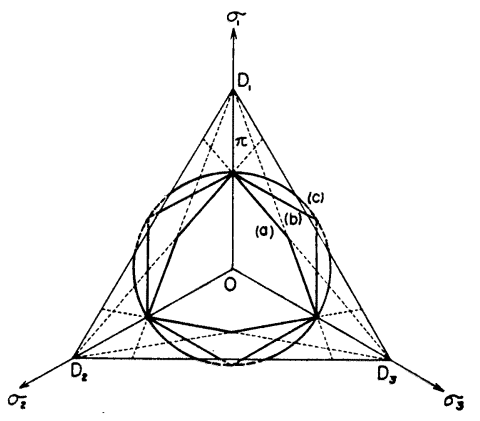

(a) Mohr-Coulomb

(b) 拡張 Tresca

(c) 拡張 von Mises 図-3

さて, 3 軸試験の圧縮 $\left(\sigma_{2}=\sigma_{3}\right)$ および引張 $\left(\sigma_{2}=\sigma_{1}\right)$ の場合の実験結果を有効応力について考察すると, 図一 1 に示した Mohr-Coulomb の条件がよく適合すること が知られており，中間主応力の影響を考慮した (b)，(c) の条件は適当でないことが示されている2)(しかし，こ のことについては $\operatorname{Roscoe}^{3)}$ などの異論もある)。一方, 塑性理論を展開するためには（c）の拡張 von Mises の 条件が最も便利で合理性があり, Drucker と Prager $^{4}$ や山口教授 ${ }^{5}$ らによって応用されている。また，星埜教 授 ${ }^{6)}$ の理論による降伏条件式も(c) と考えることができ る。さらに最近， 3 軸試験における中間主灾力の影響に 関する研究が進み, Kirkpatrick ${ }^{7}, \mathrm{Wu}^{8}$ ) は内外圧を変 えることのできる中空円筒供試体による 3 軸試験を行な

* 図一3 は, 3 軸試験の圧縮の場合の条件が同一となるよう に画いてある。したがって, この場合

$$
\begin{aligned}
k_{a} & =\frac{3 k_{b}}{2+k_{b}}=\frac{3 k_{c}}{2 \sqrt{2}+k_{c}}, \\
\sin \varphi_{a} & =\frac{3 \sin \varphi_{b}}{3+\sin \varphi_{b}}=\frac{3 \sin \varphi_{c}}{3+\sin \varphi_{c}}
\end{aligned}
$$

である。Bishop ${ }^{2)}$ は, この図において (b), (c) の場合, 主 応力が負の領域に入り不合理としているが, $k_{a}, k_{b}, k_{c}$ の間 の関係は上記のものが必ずしも必然ではなく, 事実後述す る別の関係を仮定すれば，このようなことは起こらない。

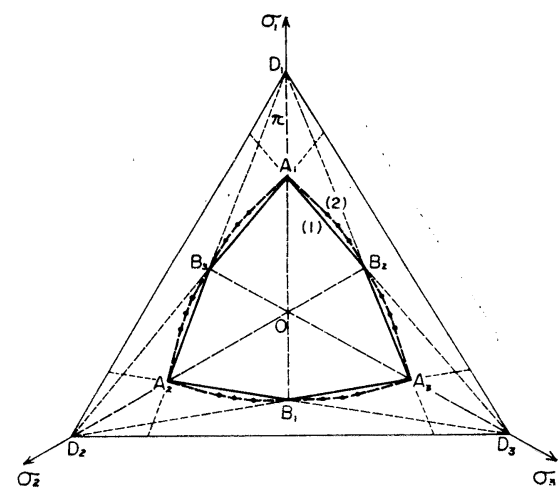

(1) Mohr-Coulomb

（2）実験結果 (Kirkpatrick ${ }^{7)}$ による)

図-4

い, また，柴田教授ら ${ }^{9}$ は立方体供試体に 2 方向から軸 力を加える 3 軸試験を行なった。その結果は, 材料の種 類, 実験や解析の方法などによって差異はあるが，一般 に図一4 亿示すように，6角形の頂点以外の点ではわず かにふくらみをもち，Mohr-Coulomb の条件からやや はずれることが見出された。これは中間主応力の影響の 無視できないことを示すものと思われる。

著者は以前から Mohr-Coulomb の条件の意味が式 (1.4)によって明確ではあるが, 単なる圧力とせん断力に ついてでなくテンソル量である応力の成分 $\sigma_{n}, \tau_{n}$ につ いて成立することについては若干の疑問を抱いていた。 また，後述するように，2次元の場合には（a）と（c) の条件が（(b) の条件も）全く等価となるのに 3 次元の 場合に等価とならないのは，やはり中間主応力の影響を 考慮する必要があり，(c) で考虑されていない 3 次元特 有のテンソルの不変量を加えて（c）を修正した関係式が 土の降伏条件として妥当なのではないかと考えてきた。 ここに提示する一つの試案は, このような考えに立脚し 2 次元の場合の類推から遒いたもので, 上述の実験結果 の傾向ともよく合致するものである。その合理性につい ては，なお多くの検討の余地があると思われるが，この 条件式から導いたひずみ速度場や特性方向などについて の若干の考察を 3. に述べている。

\section{2. 拡張 von Mises の条件の修正式の誘恧}

まず， 2 次元の場合の考察から始める。2 次元に直し た Mohr-Coulomb の条件は, 図一5 $\left(\overline{O P_{1}}=\sigma_{1}, \overline{O P_{2}}=\right.$ $\sigma_{2}$ ) に示すように,

$$
\frac{\sigma_{1}-\sigma_{2}}{\sigma_{1}+\sigma_{2}}=\frac{\overline{O^{\prime} Q}}{\overline{O O^{\prime}}}=\sin \varphi_{0}
$$

となる。2 次元の場合，1.に説明した 解釈にしたがえ ば，他の 2 条件 (b)，(c) も式 (2.1) と全く同一式とな るが, いま式 (2.1) の条件に次のような別の幾何学的表 


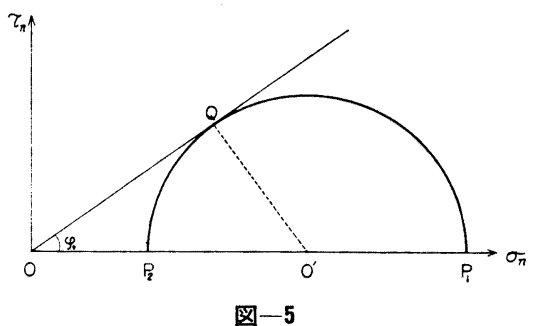

現を与えることを考える ${ }^{10)}$ 。

応カテンソル $\sigma$ は, symbolic 表現によって

$$
\begin{aligned}
& \sigma=p I+\sigma_{D} \\
& p=\frac{1}{2} \operatorname{tr} \sigma=\frac{\sigma_{1}+\sigma_{2}}{2} .
\end{aligned}
$$

と分解され ( $I$ は単位テンソル), $p$ は平均応力と呼ば れるスカラー不変量, $\sigma_{D}$ は偏差応力と呼ばれそのトレ 一スが 0 のテンソルである。 $p$ は体積変化に， $\sigma_{D}$ は形 状変化にそれぞれ対応している。また， $\sigma_{D}$ について複 内積**をつくれば,

$$
\sigma_{D} \cdot \sigma_{D}=\left(\sigma_{1}-p\right)^{2}+\left(\sigma_{2}-p\right)^{2}
$$

となり,これは形状変化の弾性ひずみエネルギーに対応 し, この值がある限界值に達すると降伏が起こるとする のが周知の von Mises の条件（拡張でない）である。 式 (2.4)を

$$
\sigma_{D} \cdot \sigma_{D}=2 J_{2}
$$

とおけば, $J_{2}$ は $\sigma_{D}$ の(したがって。の第 2 の) スカ ラー不変量であり， $\sigma_{D}$ の 2 個の主応力（偏差主応力） を

$$
\left.\begin{array}{l}
\sigma_{1}{ }^{\prime}=\sigma_{1}-p=\frac{\sigma_{1}-\sigma_{2}}{2}, \\
\sigma_{2}{ }^{\prime}=\sigma_{2}-p=\frac{\sigma_{2}-\sigma_{1}}{2}\left(=-\sigma_{1}{ }^{\prime}\right)
\end{array}\right\}
$$

とおけば,

$$
\begin{aligned}
& J_{2}=\frac{1}{2}\left(\sigma_{1}{ }^{2}+\sigma_{2}{ }^{2}\right)=-\sigma_{1}{ }^{\prime} \sigma_{2}{ }^{\prime} \\
& =\frac{1}{4}\left(\sigma_{1}-\sigma_{2}\right)^{2}
\end{aligned}
$$

である。 $J_{2}$ を用いれば, 式 (2.4) は

$$
\left(\sigma_{1}-p\right)^{2}+\left(\sigma_{2}-p\right)^{2}=2 J_{2}
$$

となり, 二つの不変量 $p, J_{2}$ をパラメーターと考えれ ば, これは $\sigma_{1}-\sigma_{2}$ 平面で $P(p, p)$ を中心とし $R=$ $\sqrt{2 J_{2}}$ を半径とする円を示す。この円の中心 $P$ は, 図 -6 に示寸ように, 原点から $\sqrt{2} p$ の距離にあり, 原

$* \operatorname{tr} \sigma$ は $\sigma$ の対角線成分の和で, $\sigma$ のトレースと呼ばれるス カラー不変量である。下の複内積を用いれば, $\operatorname{tr} \sigma=\sigma \cdot \cdot I$

と記すこともできる。

** 二つのテンソル $\alpha=\left(\alpha_{i j}\right), \beta=\left(\beta_{i j}\right)$ に対し, その複内積は

$$
\alpha \cdot \beta=\sum_{i, j=1}^{n} \alpha_{i j} \beta_{i j}
$$

ただし $n$ は次元数，と定義され，座標のとり方に関係しな ふスカラーとなる。

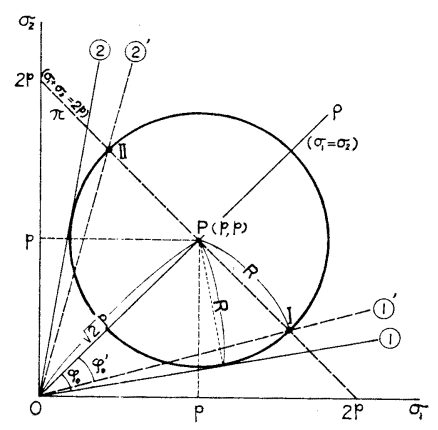

図一6

点から二つの接線を引けば（これは 2 次元的円錐面）, その中心角（接線と中心線 $\rho$ とのなす角度） $\varphi$ が限界 值 $\varphi_{0}$ に達寸ることが式 (2.1) の条件と同等であること は明らかである。なぜなら

$$
\sin \varphi=\frac{R}{\overline{O P}}=\frac{\frac{1}{\sqrt{2}}\left(\sigma_{1}-\sigma_{2}\right)}{\sqrt{2} p}=\frac{\sigma_{1}-\sigma_{2}}{\sigma_{1}+\sigma_{2}} \cdots \cdots
$$

したがって, 式 (2.1) の条件は, $p$ をパラメーターと して

$$
\left(\sigma_{1}-p\right)^{2}+\left(\sigma_{2}-p\right)^{2}=2 p^{2} \sin ^{2} \varphi_{0}
$$

と記すことができる。ここで注意すべきことは， $\varphi=\varphi_{0}$ の場合, 式 (2.10) を満足するすべての $\sigma_{1}, \sigma_{2}$ が, すな わち図一6 の円上のすべての点が降伏に達するのではな いことである。 $\sigma_{1}, \sigma_{2}$ の間には式 $(2.3)$ の従属関係があ るので, 降伏に達するのはこの関係を満足する, すなお ち 図一6 の直線 $\pi$ 上にある, 円周上の 2 点 I, II だけで ある。したがって, 実際の降伏限界線は, 図一6におけ る (1), (2) ではなく (1)', (2) であり, その中心角は

$$
\varphi_{0}{ }^{\prime}=\tan ^{-1}\left(\sin \varphi_{0}\right) \cdots \cdots \cdots \cdots \cdots \cdots \cdots \cdots \cdots \cdots \cdots \cdots \cdots \cdots \cdots \cdots \cdots \cdots \cdots
$$

となっている。このように, $p$ を任意のパラメーターと して式 (2.10) を降伏条件と考える場合は, 式 (2.3) も 連立させて考えなければならない。式 $(2.10)$ を $p$ と $J_{2}$ との関係式として書き直せば，

$$
\sqrt{J_{2}}=p \sin \varphi_{0}
$$

が降伏条件となる。

さて, 以上 2 次元の場合について行なった考察を, 3 次元の場合に移行させれば次のようになる。まず，式 (2.2), (2.3) は

$$
\begin{aligned}
& \sigma=p I+\sigma_{D} \ldots \ldots \ldots \ldots \ldots \ldots \ldots \ldots \\
& p=\frac{1}{3} \operatorname{tr} \sigma=\frac{\sigma_{1}+\sigma_{2}+\sigma_{3}}{3}
\end{aligned}
$$

となり(ただし $I$ は 3 次元の単位テンソル), $p, \sigma_{D}$ に ついての性質は前と同じである。式 (2.4) は

$$
\sigma_{D} \cdot \sigma_{D}=\left(\sigma_{1}-p\right)^{2}+\left(\sigma_{2}-p\right)^{2}+\left(\sigma_{3}-p\right)^{2}
$$

となり, 前と同様,式 (2.5) によってスカラー不変量 $J_{2}$ を定義すれば， $\sigma_{D}$ の 3 個の主応力 


$$
\left.\begin{array}{l}
\sigma_{1}{ }^{\prime}=\sigma_{1}-p=\frac{2 \sigma_{1}-\sigma_{2}-\sigma_{3}}{3}, \\
\sigma_{2}{ }^{\prime}=\sigma_{2}-p=\frac{2 \sigma_{2}-\sigma_{3}-\sigma_{1}}{3}, \\
\sigma_{3}{ }^{\prime}=\sigma_{3}-p=\frac{2 \sigma_{3}-\sigma_{1}-\sigma_{2}}{3}
\end{array}\right\}
$$

により

$$
\begin{aligned}
J_{2} & =\frac{1}{2}\left({\sigma_{1}}{ }^{2}+{\sigma_{2}}{ }^{2}+{\sigma_{3}}^{2}\right)=-\sigma_{1}{ }^{\prime}{\sigma_{2}}^{\prime}-{\sigma_{2}}{ }^{\prime} \sigma_{3}{ }^{\prime}-{\sigma_{3}}{ }^{\prime} \sigma_{1}{ }^{\prime} \\
& =\frac{1}{6}\left\{\left(\sigma_{1}-\sigma_{2}\right)^{2}+\left(\sigma_{2}-\sigma_{3}\right)^{2}+\left(\sigma_{3}-\sigma_{1}\right)^{2}\right\}(2.16)
\end{aligned}
$$

と書くことができる*。式 (2.8) は

$$
\left(\sigma_{1}-p\right)^{2}+\left(\sigma_{2}-p\right)^{2}+\left(\sigma_{3}-p\right)^{2}=2 J_{2}
$$

となり，これは $\sigma_{1}, \sigma_{2}, \sigma_{3}$ を座標軸とする 3 次元空間で， $P(p, p, p)$ を中心とし $R=\sqrt{2 J_{2}}$ を半径とする球を示 す。図一7 に示すように, この球の中心 $P$ は原点から $\sqrt{3} p$ の距離にあるので, 式 $(2.10)$ にならい

$$
\left(\sigma_{1}-p\right)^{2}+\left(\sigma_{2}-p\right)^{2}+\left(\sigma_{3}-p\right)^{2}=3 p^{2} \sin ^{2} \varphi_{0}
$$

を降伏条件と考えれば，その幾何学的解釈は, 原点を頂 点とし, 式 (1.7) で示される直線 $\rho$ を軸線, $\varphi_{0}$ を中心 角（錐面の母線と軸線とのなす角度）とする円錐面に式 (2.17) で示される球が接するようになることが降伏条 件と考えることができる（図一7 参照）。ただしこの場 合も 2 次元の場合と同様, $p$ を任意のパラメーターとし て式 (2.18) を満足するすべての $\sigma_{1}, \sigma_{2}, \sigma_{3}$ が，すなわ ち図一7に示す球面上のすべての点が，降伏状態にある のではない。 $\sigma_{1}, \sigma_{2}, \sigma_{3}$ の間には式 $(2.13)$ に示す従属関 係があるので, 図一7 における平面 $\pi$ (式 (2.13) で示 される) と球面との交線（これは半径

$$
R=\sqrt{3} p \sin \varphi_{0}
$$



図-7

* $\tau_{m}=\sqrt{\frac{2}{3} J_{2}}$ は 8 面体せ九断応力と呼ばれている。
の円周となる）上の点だけが降伏状態にあるのである。 したがって, 実際の降伏曲面は $\rho$ を軸線とし, $\varphi_{0}{ }^{\prime}=$ $\tan ^{-1}\left(\sin \varphi_{0}\right)$ を中心角とする円錐面となることに注意す る。式 (2.18) は $J_{2}$ を用いれば,

$$
\sqrt{2 J_{2}}=\sqrt{3} p \sin \varphi_{0}
$$

となり, 応力テンソル $\sigma$ の二つの不変量 $p, \sqrt{J_{2}}$ の間 の単純な比例関係を示す式である。式 (2.13), (2.16) によって書きあらためれば,

$$
\frac{\sqrt{\left(\sigma_{1}-\sigma_{2}\right)^{2}+\left(\sigma_{2}-\sigma_{3}\right)^{2}+\left(\sigma_{3}-\sigma_{1}\right)^{2}}}{\sigma_{1}+\sigma_{2}+\sigma_{3}}=\sin \varphi_{0}
$$

となり，(c) の拡張 von Mises の条件式 (1.3) におい て $k_{c}=\sin \varphi_{0}$ としたものにほかならない。

以上のように, 2 次元の場合から類推すれば, $\pi$-平面 の降伏曲線は式（2.19）で示される円となるが，ここで $\pi$ 一平面上の降伏曲線をさらに一般的に考察するため, 図 一8 に示すような $x-y$ 座標を導入する。この場合, 原 点 $P$ は $\rho$ との交点, $y$ 軸は $\sigma_{1}$ 軸の投影で, 図の $D_{i}$ はそれぞれ $\sigma_{i}$ 軸との交点である。 $\pi$-平面上にある $\sigma_{1}$, $\sigma_{2}, \sigma_{3}$ の值とこの $x-y$ 座標との関係は,

$$
\left.\begin{array}{l}
\sigma_{1}{ }^{\prime}=\sigma_{1}-p= \\
\sigma_{2}{ }^{\prime}=\sigma_{2}-p=-\frac{\sqrt{\frac{2}{3}} y,}{\sqrt{2}} x-\frac{1}{\sqrt{6}} y, \\
\sigma_{3}{ }^{\prime}=\sigma_{3}-p=-\frac{1}{\sqrt{2}} x-\frac{1}{\sqrt{6}} y
\end{array}\right\}
$$

となるので，たとえば式 (1.1) の条件の一つ

$$
\frac{\sigma_{1}-\sigma_{2}}{\sigma_{1}+\sigma_{2}}=\sin \varphi_{a}
$$

は, $\pi$-平面上では

$$
\frac{1+\sin \varphi_{a}}{\sqrt{2}} x+\frac{3-\sin \varphi_{a}}{\sqrt{6}} y-2 p \sin \varphi_{a}=0
$$

（図一8 に示す直線 $A_{1} B_{2}$ ) となり, (a) の MohrCoulomb の条件の限界線は 6 角形 $A_{1} B_{2} A_{3} B_{1} A_{2} B_{3}$ に

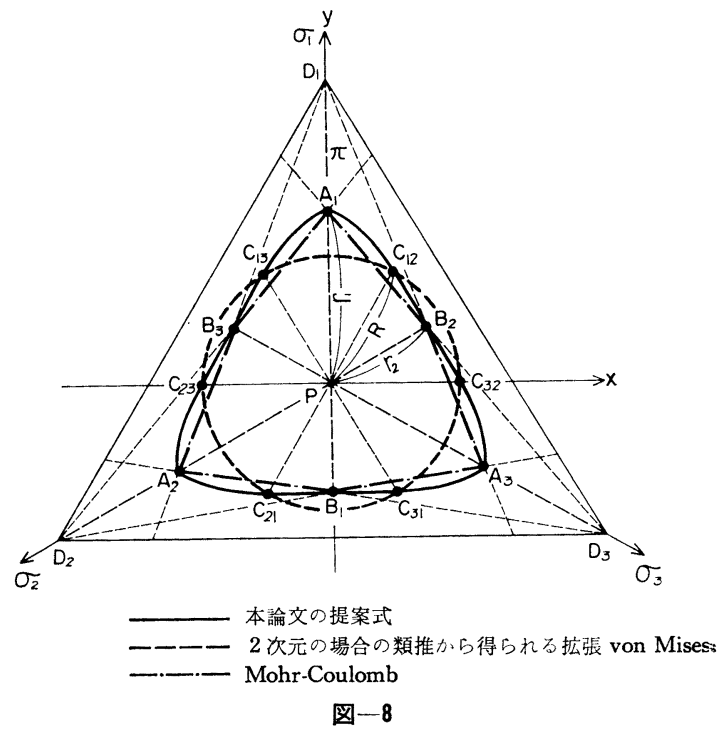


よって示されることがわかる。この 6 角形の頂点は原点 から

$$
\left.\begin{array}{c}
A_{i}: r_{1}=\frac{2 \sqrt{6} p \sin \varphi_{a}}{3-\sin \varphi_{a}} \\
B_{i}: r_{2}=\frac{2 \sqrt{6} p \sin \varphi_{a}}{3+\sin \varphi_{a}}
\end{array}\right\}
$$

の距離にある。ここで, この限界線を先に求めた式 (2.19) の円と比較するために， $\varphi_{a}$ と $\varphi_{0}$ との対応を定 めなければならないが, Mohr-Coulomb の条件が, 3 軸試験の圧縮, 引張いずれの場合にも実験值とよく適合 することを考え， $\varphi_{a}$ と $\varphi_{0}$ との対応を式 (1.3) の $\varphi_{c}$ と式 (2.21) と式 (2.21) の $\varphi_{0}$ との対応と同一になる ようにするのが最も適当であろう。このことは式 (1.6) によって, 3 軸試験の圧縮 $\left(\sigma_{2}=\sigma_{3}\right)$ と引張 $\left(\sigma_{2}=\sigma_{1}\right)$ の いずれの場合にも同一の $\varphi_{2}=\varphi_{c}$ を与えられるが, この $\varphi_{2}$ を $\varphi_{a}$ と等置したことと同等である。こうして

$$
\sin \varphi_{a}=\frac{3}{2 \sqrt{2}} \sin \varphi_{0}
$$

在得るが, この結果, 式 (2.23) は

$$
\left.\begin{array}{l}
r_{1}=\frac{\sqrt{3} p \sin \varphi_{0}}{1-\frac{\sqrt{2}}{4} \sin \varphi_{0}}=\frac{R}{1-\frac{\sqrt{2}}{4} \sin \varphi_{0}}, \\
r_{2}=\frac{\sqrt{3} p \sin \varphi_{0}}{1+\frac{\sqrt{2}}{4} \sin \varphi_{0}}=\frac{R}{1+\frac{\sqrt{2}}{4} \sin \varphi_{0}}
\end{array}\right\} \cdots
$$

々書き直すことができる。この場合, Mohr-Coulombの 6 角形の 3 頂点 $A_{i}$ は式 (2.19) の拡張 von Mises の 円の外側に, 他の 3 頂点 $B_{i}$ は内側にあることがわかる。

以上の考察から, 降伏限界曲線として最も妥当なもの は, Mohr-Coulomb の 6 角形の頂点を通り, しかも, その他の点では図一4の実験結果の傾向に合致するよう に, 式 (2.19) の円を修正したものと考えられる。いま, $\pi$-平面に極座標 $r, \theta$ (ただし， $\theta$ は $x$ 軸から時計と反 対迴りにはかる) を導入すれば, 式 (2.25) から, 上記 の条件を満足する最も単純なものとして，

$$
r=\frac{\sqrt{3} p \sin \varphi_{0}}{1+\frac{\sqrt{2}}{4} \sin \varphi_{0} \sin 3 \theta}
$$

が得られ，これを降伏限界曲線と考えるのが適当であろ う。ここで, 式 (2.22) も極座標に書きあらためれば,

$$
\left.\begin{array}{rl}
{\sigma_{1}}^{\prime} & =\sqrt{\frac{2}{3}} r \cos \left(\theta-\frac{\pi}{2}\right), \\
{\sigma_{2}}^{\prime} & =\sqrt{\frac{2}{3}} r \cos \left(\theta+\frac{5}{6} \pi\right), \\
{\sigma_{3}}^{\prime} & =\sqrt{\frac{2}{3}} r \cos \left(\theta+\frac{\pi}{6}\right)
\end{array}\right\}
$$

となるが， $\frac{\pi}{2},-\frac{5}{6} \pi,-\frac{\pi}{6}$ は図一8において，それぞ れ， $\sigma_{1}, \sigma_{2}, \sigma_{3}$ 軸の投影が $x$ 軸となす角度であることに注 意する。 $\sigma_{D}$ について， 2 次元では考えることができな いが 3 次元の場合に始めて考えることのできる $\sigma_{D}$ の
（したがって。の第 3 の）スカラ一不変量

$$
\begin{aligned}
J_{3} & =\sigma_{1}{ }^{\prime} \sigma_{2}{ }^{\prime} \sigma_{3}{ }^{\prime} \\
& =\frac{1}{27}\left(2 \sigma_{1}-\sigma_{2}-\sigma_{3}\right)\left(2 \sigma_{2}-\sigma_{3}-\sigma_{1}\right)\left(2 \sigma_{3}-\sigma_{1}-\sigma_{2}\right)
\end{aligned}
$$

を導入すれば, 式 (2.27) より

$$
\begin{gathered}
J_{3}=\left(\sqrt{\frac{2}{3}} r\right)^{3} \cos \left(\theta-\frac{\pi}{2}\right) \cos \left(\theta+\frac{5}{6} \pi\right) \cos \left(\theta+\frac{\pi}{6}\right) \\
=-\frac{1}{6} \sqrt{\frac{2}{3}} r^{3} \sin 3 \theta \ldots \ldots \ldots \ldots \ldots \ldots \ldots(2.29)
\end{gathered}
$$

を得るが，同様に式 (2.16) から

$$
J_{2}=\frac{1}{2} r^{2}
$$

を得るので，

$$
\frac{J_{3}}{J_{2}}=-\frac{1}{3} \sqrt{\frac{2}{3}} r \sin 3 \theta
$$

また，

$$
\left.\begin{array}{c}
r=\sqrt{2 J_{2}}, \\
\sin 3 \theta=-\frac{3 \sqrt{3}}{2} \cdot \frac{J_{3}}{J_{2}^{3 / 2}}
\end{array}\right\}
$$

などを得る。式 (2.32) を用いて式 (2.26) を書きあら ためれば,

$$
\sqrt{2 J_{2}}=\frac{\sqrt{3} p \sin \varphi_{0}}{1-\frac{3}{4} \sqrt{\frac{3}{2}} \cdot \frac{J_{3}}{J_{2}^{3 / 2}} \sin \varphi_{0}}
$$

すなわち，

$$
\sqrt{2 J_{2}}=\sqrt{3} \sin \varphi_{0}\left(p+\frac{3}{4} \cdot \frac{J_{3}}{J_{2}}\right) \cdots \cdots(2
$$

が得られる。

式 (2.33) は, 式 (2.20) を 3 次元特有の不変量 $J_{3}$ に よって単純に修正したもので, しかも図一8に示すよう に，Mohr-Coulomb の 6 角形に外接し，実験結果の傾 向ともよく適合する条件を与え, 粘着力のない場合の 土の降伏条件として妥当なものではないかと考えられ る。式 (2.33) は, 一つの偏差主応力が 0 となる場合は

$$
J_{3}=0, \sin 3 \theta=0
$$

となって, 右辺の付加項がなくなり式 (2.20) と一致す るが, これは図一8の $C_{i j}$ 点 $\left(\sigma_{i}>\sigma_{k}>\sigma_{j}, \sigma_{k}=1 / 2\right.$ $\left(\sigma_{i}+\sigma_{j}\right)$, ただし $i, j, k$ は $1,2,3$ の任意の順列) に対 応している。

\section{3. 考察}

前章で導いた降伏条件式 (2.33) は，2 次元の場合の 式 (2.12) から類推した 3 次元の場合の式 (2.20)（拡張 von Mises の条件) を修正したものであるが，付加項 $3 / 4 \cdot J_{3} / J_{2}$ は 3 次元の場合に始めて考えられる量である から, 2 次元の場合に存在しないのは当然である。以下, 従来拡張 von Mises の条件に対して行なわれている塑 
性理論の考察 ${ }^{4), 5)}$ が, 本論の式 (2.33) の場合, いかに 修正されるか, 上記の付加項の影響を中心に述べること にする。

\section{（1）応力の特性方向}

一般に 3 次元問題では特性方向は曲面群となるが, 解 析を容易にするため, 2 次元問題に直して特性方向の考 察を行なら。

中間主応力を $\sigma_{2}$, すなわち

$$
\sigma_{1} \geq \sigma_{2} \geq \sigma_{3}
$$

とし， $\sigma_{2}$ に対応する主軸IIは固定して，これに垂直な 平面（主軸 I, IIIを含む）内で 2 次元的応力

$$
\sigma^{\prime}=\left(\begin{array}{ll}
\sigma_{x} & \tau_{x y} \\
\tau_{x y} & \sigma_{y}
\end{array}\right)
$$

ただし，

$$
\sigma=\left(\begin{array}{cc:c}
\sigma^{\prime} & 0 \\
\hdashline & 0 \\
\hdashline 0 & 0 & \sigma_{2}
\end{array}\right)
$$

を考察する。 $\sigma^{\prime}$ の二つの不変量を $P^{\prime}, J_{2}^{\prime}$ とすれば, 式 (2.3), (2.7) より,

$$
\begin{aligned}
p^{\prime} & =\frac{1}{2}\left(\sigma_{1}+\sigma_{3}\right)=\frac{1}{2}\left(\sigma_{x}+\sigma_{y}\right) \cdots \cdots \cdots \cdots \cdots \\
\sqrt{J_{2}{ }^{\prime}}=\frac{1}{2}\left(\sigma_{1}-\sigma_{3}\right) & =\frac{1}{2} \sqrt{\left(\sigma_{x}-\sigma_{y}\right)^{2}+4 \tau_{x y}{ }^{2}}
\end{aligned}
$$

であるから， ををつのパラメーターとして次のように おくことができる*。

$$
\left.\begin{array}{l}
\sigma_{1}=p^{\prime}+\sqrt{J_{2}^{\prime}}, \\
\sigma_{2}=p^{\prime}+\sqrt{J_{2}^{\prime}} \cos \alpha, \\
\sigma_{3}=p^{\prime}-\sqrt{J_{2}^{\prime}}
\end{array}\right\}
$$

ゆえに, 式 (2.13) の $p$, および式 (2.15) の偏差主応 力はそれぞれ

$$
\begin{aligned}
& p=p^{\prime}+\frac{1}{3} \sqrt{J_{2}{ }^{\prime}} \cos \alpha \cdots \cdots \cdots \cdots \cdots \cdots . \\
& \sigma_{1}{ }^{\prime}=\sigma_{1}-p=\sqrt{J_{2}{ }^{\prime}}\left(1-\frac{1}{3} \cos \alpha\right), \\
& \sigma_{2}{ }^{\prime}=\sigma_{2}-p=\sqrt{J_{2}{ }^{\prime}} \frac{2}{3} \cos \alpha, \\
& \sigma_{3}{ }^{\prime}=\sigma_{3}-p=\sqrt{J_{2}{ }^{\prime}}\left(-1-\frac{1}{3} \cos \alpha\right)
\end{aligned}
$$

となり, 式 (2.16), (2.28) より, $\sigma_{D}$ の二つの不変量 $J_{2}, J_{3}$ は

$$
\begin{array}{r}
J_{2}=\frac{1}{2}\left({\sigma_{1}}^{\prime}{ }^{2}+{\sigma_{2}}{ }^{2}+{\sigma_{3}}^{2}\right)=J_{2}{ }^{\prime}\left(1+\frac{1}{3} \cos ^{2} \alpha\right) \\
\cdots \cdots \cdots \cdots \cdots \cdots \cdots \cdots \cdots \cdots \cdots \cdots \cdots \cdots \cdots \cdots \cdots \\
J_{3}=\sigma_{1}{ }^{\prime} \sigma_{2}{ }^{\prime} \sigma_{3}{ }^{\prime}=-\frac{2}{3} J_{2}{ }^{\prime} \frac{3}{2} \cos \alpha\left(1-\frac{1}{9} \cos ^{2} \alpha\right)
\end{array}
$$

\footnotetext{
* $\cos \alpha=\frac{2 \sigma_{2}-\sigma_{3}-\sigma_{1}}{\sigma_{1}-\sigma_{3}}$ は Lode のパラメーターと呼ばれてい
}

また，

$$
\frac{J_{3}}{J_{2}}=-\frac{2}{3} \sqrt{J_{2}^{\prime}} \cos \alpha \frac{1-\frac{1}{9} \cos ^{2} \alpha}{1+\frac{1}{3} \cos ^{2} \alpha}
$$

と記すことができる。

これらの諸式を式 (2.33) に代入すれば, 式 (2.33) は $p^{\prime}, J_{2}^{\prime}$ に関する次の関係式に書き改めることができ る。

$$
\sqrt{J_{2}{ }^{\prime}}=p^{\prime} \sin \varphi_{0}{ }^{\prime}
$$

ただし，

$$
\sin \varphi_{0}^{\prime}=\frac{\sqrt{3} \sin \varphi_{0}}{\sqrt{2\left(1+\frac{1}{3} \cos ^{2} \alpha\right)}+\frac{\sqrt{3}}{6} \cdot \frac{\cos \alpha \sin ^{2} \alpha}{1+\frac{1}{3} \cos ^{2} \alpha} \sin \varphi_{0}}
$$

式 (3.12) は式 (2.12) と全く同形であるが，式 (3.13) に示すように 3 次元的応力状態（ $\alpha$ がその パラ メーター）が異なると $\varphi_{0}^{\prime}$ は変化することに注意する*。 たとえば,

i ） $\alpha=0$ または $2 \pi\left(\sigma_{2}=\sigma_{1}\right.$ または $\sigma_{2}=\sigma_{3}$ で軸対称 の場合)：

$$
\text { ii } \quad \begin{aligned}
& \sin \varphi_{0}{ }^{\prime}=\frac{3}{2 \sqrt{2}} \sin \varphi_{0} \ldots \ldots \ldots \ldots \ldots . . . \\
& \sin \varphi_{0}{ }^{\prime}=\sqrt{\frac{3}{2}} \sin \varphi_{0} \ldots \ldots \ldots \ldots \ldots \ldots \ldots
\end{aligned}
$$

となる。式 (2.33) で付加項がない抎張 von Mises の 条件式 (2.20) の場合にも, 同様の計算によって式 (3.12) の形を導くことができるが，この場合の $\varphi_{0}^{\prime}$ は式 (3.13) の代りに

$$
\sin \varphi_{0}{ }^{\prime}=\frac{\sqrt{3} \sin \varphi_{0}}{\sqrt{2\left(1+\frac{1}{3} \cos ^{2} \alpha\right)-\frac{\sqrt{3}}{3} \cos \alpha \sin \varphi_{0}}}
$$

となる。式 (3.16) によると, ii) の場合は式 (3.15) と 同一の結果となるが, i) の場合, $\alpha=0$ と $\alpha=2 \pi$ とで 異なった $\varphi_{0}^{\prime}$ の值を与え, 実験結果と合致しない。

さて, 式 (3.12) を

$$
\begin{aligned}
f & =f\left(\sigma_{x}, \sigma_{y}, \tau_{x y}\right)=f\left(p^{\prime}, \sqrt{J_{2}{ }^{\prime}}\right) \\
& =\sqrt{J_{2}{ }^{\prime}}-p^{\prime} \sin \varphi_{0}{ }^{\prime}=0 \ldots \ldots \ldots \ldots \ldots
\end{aligned}
$$

とおいて, この条件の下に, 平面ひずみの場合の応力の 特性方向を求めよう。物体力を無視すれば, 応力成分は Airy 関数 $F$ を用いて，

$$
\sigma_{x}=\frac{\partial^{2} F}{\partial y^{2}}, \quad \sigma_{y}=\frac{\partial^{2} F}{\partial x^{2}}, \tau_{x y}=-\frac{\partial^{2} F}{\partial x \partial y}
$$

* Bishop ${ }^{2)}$ は式 (3.13) の代りに，さらに簡単な修正式 (本 論文の記号に書きあらためれば， $k$ を定数として)

$$
\sin \varphi_{0}{ }^{\prime}=\frac{\frac{3}{2 \sqrt{2}} \sin \varphi_{0}}{1-k \sin \alpha \sin \varphi_{0}}
$$

を提案している。 
と表わせるから, 式 (3.17) は $F$ についての 2 階偏微 分方程式となり, その特性方向 $d y / d x$ は

$$
\frac{\partial f}{\partial \sigma_{y}}\left(\frac{d y}{d x}\right)^{2}+\frac{\partial f}{\partial \tau_{x y}}\left(\frac{d y}{d x}\right)+\frac{\partial f}{\partial \sigma_{x}}=0 \cdots
$$

から求められる。 $x-y$ 軸を主軸 I, III と一致させ, 特性 方向が主軸 I と $\theta$ の角度をなすとすれば, 式 (3.19) は

$$
\frac{\partial f}{\partial \sigma_{3}}(\tan \theta)^{2}+\frac{\partial f}{\partial \sigma_{1}}=0
$$

となるが, 式 (3.4), (3.5) および (3.17) より

$$
\begin{aligned}
\frac{\partial f}{\partial \sigma_{3}} & =\frac{\partial p^{\prime}}{\partial \sigma_{3}} \cdot \frac{\partial f}{\partial p^{\prime}}+\frac{\partial \sqrt{J_{2}{ }^{\prime}}}{\partial \sigma_{3}} \cdot \frac{\partial f}{\partial \sqrt{J_{2}{ }^{\prime}}} \\
& =\frac{1}{2}\left(-\sin \varphi_{0}{ }^{\prime}\right)-\frac{1}{2}=-\frac{1}{2}\left(1+\sin \varphi_{0}{ }^{\prime}\right)
\end{aligned}
$$

同様に

$$
\frac{\partial f}{\partial \sigma_{1}}=\frac{1}{2}\left(1-\sin \varphi_{0}^{\prime}\right)
$$

であるから，

$$
\begin{aligned}
& \tan \theta= \pm \sqrt{\frac{1-\sin \varphi_{0}^{\prime}}{1+\sin \varphi_{0}^{\prime}}}= \pm \tan \left(\frac{\pi}{4}-\frac{\varphi_{0}^{\prime}}{2}\right) \\
& \therefore \theta= \pm\left(\frac{\pi}{4}-\frac{\varphi_{0}{ }^{\prime}}{2}\right)
\end{aligned}
$$

を得る。この結果は, 最大の Mohr の応力円が限界線 に接する点から得られるすべり面の方向と同一となる (図-1 参照)。

\section{（2）塑性ポテンシャルとひずみ速度場}

式 (2.33)を

$$
f\left(p, J_{2}, J_{3}\right)=\sqrt{2 J_{2}}-\sqrt{3} \sin \varphi_{0}\left(p+\frac{3}{4} \cdot \frac{J_{3}}{J_{2}}\right)=0
$$

とおき,この $f$ を塑性ポテンシャルとして

$$
D \varepsilon=\frac{\partial f}{\partial \sigma} D \lambda
$$

によって, ひずみ速度場

$$
\dot{\delta}=\frac{D \varepsilon}{D t}
$$

を求めてみよう。

$\sigma$ の 3 個のスカラー不変量を

$$
\begin{aligned}
& I_{1}=\sigma_{1}+\sigma_{2}+\sigma_{3} \quad=3 p, \\
& I_{2}=\sigma_{1} \sigma_{2}+\sigma_{2} \sigma_{3}+\sigma_{3} \sigma_{1}=3 p^{2}-J_{2} \text {, } \\
& I_{3}=\sigma_{1} \sigma_{2} \sigma_{3} \quad=p^{3}-p J_{2}+J_{3}
\end{aligned}
$$

とおけば,

$$
\left.\begin{array}{l}
\frac{\partial I_{1}}{\partial \sigma}=I, \\
\frac{\partial I_{2}}{\partial \sigma}=I_{1} I-\sigma, \\
\frac{\partial I_{3}}{\partial \sigma}=I_{3} \sigma^{-1}
\end{array}\right\}
$$

* $\partial f / \partial \sigma$ は, その $i j$ 成分が $\partial f / \partial \sigma_{i j}$ で与えられるようなテ ンソルを示す。

** $\sigma^{-1}$ は $\sigma$ の逆テンソルで, $I_{3} \neq 0$ の場合に一意的に存在し, $\sigma \cdot \sigma^{-1}=\sigma^{-1} \cdot \sigma=I$ が成立する。
で,

$$
\left.\begin{array}{rl}
\sigma & =p I+\sigma_{D}, \\
I_{3} \sigma^{-1} & =p^{2} I-p \sigma_{D}+J_{3} \sigma_{D}{ }^{-1}, \\
\sigma_{D}^{-1} & =-\frac{1}{3} \cdot \frac{J_{2}}{J_{3}} I+\left(\sigma_{D}{ }^{-1}\right)_{D}
\end{array}\right\}
$$

などが成立する。式 (3.25) より

$$
\left.\begin{array}{l}
p=\frac{1}{3} I_{1}, \\
J_{2}=3 p^{2}-I_{2}, \\
J_{3}=-p^{3}+p J_{2}+I_{3}
\end{array}\right\}
$$

であるから，式 (3.26)，(3.27）を用いれば,

$$
\left.\begin{array}{rl}
\frac{\partial p}{\partial \sigma} & =\frac{1}{3} \cdot \frac{\partial I_{1}}{\partial \sigma}=\frac{1}{3} I, \\
\frac{\partial J_{2}}{\partial \sigma} & =6 p \frac{\partial p}{\partial \sigma}-\frac{\partial I_{2}}{\partial \sigma}=2 p I-(3 p I-\sigma)=\sigma_{D}, \\
\frac{\partial J_{3}}{\partial \sigma} & =\left(-3 p^{2}+J_{2}\right) \frac{\partial p}{\partial \sigma}+p \frac{\partial J_{2}}{\partial \sigma}+\frac{\partial I_{3}}{\partial \sigma} \\
& =\left(-3 p^{2}+J_{2}\right) \frac{1}{3} I+p \sigma_{D}+I_{3} \sigma^{-1}=J_{3}\left(\sigma_{D}^{-1}\right)_{D}
\end{array}\right\}
$$

となる。したがって,一般に

$$
\begin{aligned}
\frac{\partial}{\partial \sigma} f\left(p, J_{2}, J_{3}\right) & =\frac{\partial f}{\partial p} \cdot \frac{\partial p}{\partial \sigma}+\frac{\partial f}{\partial J_{2}} \cdot \frac{\partial J_{2}}{\partial \sigma}+\frac{\partial f}{\partial J_{3}} \cdot \frac{\partial J_{3}}{\partial \sigma} \\
& \left.=\frac{1}{3} \cdot \frac{\partial f}{\partial p} I+\frac{\partial f}{\partial J_{2}} \sigma_{D}+\frac{\partial f}{\partial J_{3}} \cdot J_{3}\left(\sigma_{D}\right)_{D}^{-1}\right)
\end{aligned}
$$

が成立する。ここに, 第 2 , 第 3 項はいずれも純偏差テ ンソルとなり，しかも $\sigma_{D}{ }^{-1}$ も $\sigma_{D}$ と同一主軸を有する からここして得られた $\partial f / \partial \sigma$ は $\sigma$ と同一主軸をもつ ものであることがわかる。式 (3.22) の場合は,

$$
\left.\begin{array}{l}
\frac{\partial f}{\partial p}=-\sqrt{3} \sin \varphi_{0}, \\
\frac{\partial f}{\partial J_{2}}=\frac{1}{\sqrt{2 J_{2}}}+\frac{3}{4} \sqrt{3} \sin \varphi_{0} \frac{J_{3}}{J_{2}^{2}}, \\
\frac{\partial f}{\partial J_{3}}=-\frac{3}{4} \sqrt{3} \sin \varphi_{0} \frac{1}{J_{2}}
\end{array}\right\}
$$

であるから, 式 (3.23), (3.30) より

$$
\begin{aligned}
D \varepsilon= & {\left[-\frac{\sqrt{3}}{3} \sin \varphi_{0} I+\frac{1}{\sqrt{2 J_{2}}} \sigma_{D}\right.} \\
& \left.+\frac{3}{4} \sqrt{3} \sin \varphi_{0} \frac{J_{3}}{J_{2}}\left\{\frac{1}{J_{2}} \sigma_{D}-\left(\sigma_{D}{ }^{-1}\right)_{D}\right\}\right] D \lambda
\end{aligned}
$$

が得られる。このひずみ速度場は, 前述のように $\sigma$ と同 一の主軸をもっている。さらにわかりやすく

$$
D \varepsilon=\frac{1}{3} D e I+D \varepsilon_{D}
$$

と分解すれば, $D e=\operatorname{tr} D \varepsilon$ は体積変化を, $D \varepsilon_{D}$ は純粋 な変形（せん断変形）を表わし，それぞれ

$$
D e=-\sqrt{3} \sin \varphi_{0} D \lambda
$$

$$
D \varepsilon_{D}=\left[\frac{1}{\sqrt{2 J_{2}}} \sigma_{D}+\frac{3}{4} \sqrt{3} \sin \varphi_{0} \frac{J_{3}}{J_{2}}\right.
$$

${ }^{*} \sigma_{D}{ }^{-1}$ は $\sigma_{D}$ の逆テンソル, $\left(\sigma_{D}{ }^{-1}\right)_{D}$ はその偏差部分を示す。 


$$
\text { • } \left.\left\{\frac{1}{J_{2}} \sigma_{D}-\left(\sigma_{D}^{-1}\right)_{D}\right\}\right] D \lambda
$$

と記すことができる。 $D \lambda>0$ で圧縮を正としているか ら, 式 (3.34) は体積の膨張を示し, これは土のダイレ イタンシーと呼ばれる現象を説明している゙”。また，上 記の計算過程をたどってみれば, 付加項 $3 / 4 \cdot J_{3} / J_{2}$ の影 響は, 式 (3.32) または (3.35) の 3/4 以下の項として現 われており,ダイレイタンシー De は, 拡張 von Mises の条件式 (2.20) から出発した場合と差異はない。しか し, 式 (3.35) の右辺は $\left(\sigma_{D}^{-1}\right)_{D}$ を含むので, 拡張 von Mises の条件から出発した場合のように, Reuss の関係 式 $\left(D \varepsilon_{D}\right.$ と $\sigma_{D}$ とが比例する) は成立しないことに注 意する。

式 (3.32) のひずみ速度場は, 降伏条件式を塑性ポテ ンシャルとして求めたものであるから，もし，ひずみ速 度を降伏曲面上の対応する応力の位置に図示すれば, 当 然, 降伏曲面の法線ベクトルとなっている。このこと は, 対応する応力の位置における降伏曲面上での応力の 任意の変化 $d \sigma$ に対し,

$$
D \varepsilon \cdot d \sigma=\frac{\partial f}{\partial \sigma} D \lambda \cdot d \sigma=d f D \lambda=0 \cdots
$$

となることから明らかである。式 (3.32) のひずみ速度 のもつこの性質から, 最大塑性仕事の原理や解の唯一性 などが，このひずみ速度場に対して成立することが保証 される

\section{（3）ひずみ速度場の特性方向}

前節で得られたひずみ速度場の特性方向について考察 する。解析の容易のため，（1）の応力の場合と同様に， 中間主ひずみ速度 $D \varepsilon_{2} / D t$ に対応する主軸 II を固定し, これに垂直な面内で 2 次元的な解析を行なうこととす る $^{12)}$ 。

ひずみ成分は, 変位ベクトルの成分 $u, v$ により

$$
\varepsilon_{x}=-\frac{\partial u}{\partial x}, \varepsilon_{y}=-\frac{\partial v}{\partial y}, r_{x y}=-\left(\frac{\partial v}{\partial x}+\frac{\partial u}{\partial y}\right)
$$

とおくことができ，ひずみ成分のテンソルとしての性質 から

$$
\begin{aligned}
& \sigma_{D}{ }^{-1}=\left(\begin{array}{c}
\sigma_{1}{ }^{\prime-1} \\
{\sigma_{2}}^{\prime-1} \\
{\sigma_{3}}^{\prime-1}
\end{array}\right)=\frac{1}{\sqrt{J_{2}{ }^{\prime}}} \cdot \frac{1}{\cos \alpha\left(1-\frac{1}{9} \cos ^{2} \alpha\right)}\left(\begin{array}{c}
\cos \alpha\left(1+\frac{1}{3} \cos \alpha\right) \\
\frac{3}{2}\left(1-\frac{1}{9} \cos ^{2} \alpha\right) \\
-\cos \alpha\left(1-\frac{1}{3} \cos \alpha\right)
\end{array}\right) \\
& \therefore\left(\sigma_{D^{-1}}\right)_{D}=\frac{1}{\sqrt{\sqrt{2}^{\prime}}} \cdot \frac{1}{\cos \alpha\left(1-\frac{1}{9} \cos ^{2} \alpha\right)}\left(\begin{array}{c}
-\frac{1}{2}+\cos \alpha+\frac{1}{6} \cos ^{2} \alpha \\
1-\frac{1}{3} \cos ^{2} \alpha \\
-\frac{1}{2}-\cos \alpha+\frac{1}{6} \cos ^{2} \alpha
\end{array}\right)
\end{aligned}
$$$$
\left.\begin{array}{rl}
\varepsilon_{x}+\varepsilon_{y} & =\varepsilon_{1}+\varepsilon_{3}, \\
\varepsilon_{x}-\varepsilon_{y} & =\left(\varepsilon_{1}-\varepsilon_{3}\right) \cos 2 \theta \\
r_{x y} & =-\left(\varepsilon_{1}-\varepsilon_{3}\right) \sin 2 \theta
\end{array}\right\}
$$

が成り立つ。ここに， $\varepsilon_{1}, \varepsilon_{3}$ は二つの主ひずみ $\left(\varepsilon_{1}>\right.$ $\left.\varepsilon_{3}\right), \theta$ は $x$ 軸が主軸I となす角度（時計廻り正）であ る。

$$
\sin \psi=-\frac{\varepsilon_{1}+\varepsilon_{3}}{\varepsilon_{1}-\varepsilon_{3}}
$$

とおけば, 式 (3.37), (3.38) より, $u, v$ に関する連立 偏微分方程式

$$
\left.\begin{array}{l}
\frac{\partial u}{\partial x}+\cot 2 \theta\left(\frac{\partial u}{\partial y}+\frac{\partial v}{\partial x}\right)-\frac{\partial v}{\partial y}=0 \\
\frac{\partial u}{\partial x}-\sin \psi \operatorname{cosec} 2 \theta\left(\frac{\partial u}{\partial y}+\frac{\partial v}{\partial x}\right)+\frac{\partial v}{\partial y}=0
\end{array}\right\}
$$

が得られ，その特性方向 $d y / d x$ は

$(\cot 2 \theta+\sin \psi \operatorname{cosec} 2 \theta)\left(\frac{d y}{d x}\right)^{2}+2\left(\frac{d y}{d x}\right)$

$$
-(\cot 2 \theta-\sin \psi \operatorname{cosec} 2 \theta)=0
$$

で与えられる。 $x$ 軸と主軸 I とを一致させれば $(\theta=0)$,

$$
(1+\sin \psi)\left(\frac{d y}{d x}\right)^{2}-(1-\sin \psi)=0
$$

となり，

$$
\frac{d y}{d x}= \pm \sqrt{\frac{1-\sin \psi}{1+\sin \psi}}= \pm \tan \left(\frac{\pi}{4}-\frac{\psi}{2}\right)
$$

を得るから，ひずみの特性方向は, 主軸 I と $\pm(\pi / 4-$ $\psi / 2)$ の角度をなす方向であることがわかる。上記の解 析は $D \varepsilon$ についても同様であるから，

$$
\sin \psi=-\frac{D \varepsilon_{1}+D \varepsilon_{3}}{D \varepsilon_{1}-D \varepsilon_{3}}
$$

を計算し, $D \varepsilon$ の特性方向を与える $\psi$ を求めることと する。

座標軸を主軸にとれば，テンソルは対角線成分だけと なるから, 式 (3.8) は

$$
\sigma_{D}=\left(\begin{array}{c}
\sigma_{1}{ }^{\prime} \\
\sigma_{2}{ }^{\prime} \\
\sigma_{3}{ }^{\prime}
\end{array}\right)=\sqrt{J_{2}{ }^{\prime}}\left(\begin{array}{c}
1-\frac{1}{3} \cos \alpha \\
\frac{2}{3} \cos \alpha \\
-1-\frac{1}{3} \cos \alpha
\end{array}\right) \cdots \cdots(
$$

と略記することができ，同様の略記法により

等を得, さらに式 (3.9)，(3.11）を用いることにより，式 (3.32) は 


$$
D \varepsilon=\left[\frac{1}{\sqrt{2\left(1+\frac{1}{3} \cos ^{2} \alpha\right)}}\left(\begin{array}{c}
1-\frac{1}{3} \cos \alpha \\
\frac{2}{3} \cos \alpha \\
-1-\frac{1}{3} \cos \alpha
\end{array}\right)-\frac{\sqrt{3}}{18} \cdot \frac{\sin \varphi_{0}}{\left(1+\frac{1}{3} \cos ^{2} \alpha\right)^{2}}\left(\begin{array}{c}
\frac{1}{2}\left(21+2 \cos ^{2} \alpha+\cos ^{4} \alpha\right)-4 \cos ^{3} \alpha \\
-3+10 \cos ^{2} \alpha+\cos ^{4} \alpha \\
\frac{1}{2}\left(21+2 \cos ^{2} \alpha+\cos ^{4} \alpha\right)+4 \cos ^{3} \alpha
\end{array}\right)\right] D \lambda
$$

と記すことができる。したがって

$$
D \varepsilon_{2}=\left\{\frac{1}{\sqrt{2\left(1+\frac{1}{3} \cos ^{2} \alpha\right)}} \cdot \frac{2}{3} \cos \alpha-\frac{\sqrt{3}}{18} \cdot \frac{\sin \varphi_{0}}{\left(1+\frac{1}{3} \cos ^{2} \alpha\right)^{2}}\left(-3+10 \cos ^{2} \alpha+\cos ^{4} \alpha\right)\right\} D \lambda
$$

また，簡単な計算により，

$$
\begin{aligned}
& D \varepsilon_{1}+D \varepsilon_{3}=-\sqrt{3} \sin \varphi_{0} D \lambda-D \varepsilon_{2}, \\
& \left.D \varepsilon_{1}-D \varepsilon_{3}=\left\{\sqrt{2\left(1+\frac{1}{3} \cos ^{2} \alpha\right)}+\frac{\sqrt{3}}{6} \cdot \frac{\cos \alpha \sin ^{2} \alpha}{1+\frac{1}{3} \cos ^{2} \alpha} \sin \varphi_{0}\right\} D \lambda-D \varepsilon_{2} \cos \alpha\right\}
\end{aligned}
$$

を得る。

平面ひずみの場合は,

$$
D \varepsilon_{2}=0
$$

であるから，この場合の $\alpha$ は式 (3.49) より

$$
\frac{2 \sqrt{6} \cos \alpha\left(1+\frac{1}{3} \cos ^{2} \alpha\right)^{\frac{3}{2}}}{-3+10 \cos ^{2} \alpha+\cos ^{4} \alpha}=\sin \varphi_{0}
$$

を満足しなければならない。また，特性方向を示す は式 (3.44) に式 (3.50) を代入することにより,

$$
\sin \psi=\frac{\sqrt{3} \sin \varphi_{0}}{\sqrt{2\left(1+\frac{1}{3} \cos ^{2} \alpha\right)+\frac{\sqrt{3}}{6} \cdot \frac{\cos \alpha \sin ^{2} \alpha}{1+\frac{1}{3} \cos ^{2} \alpha} \sin \varphi_{0}}}
$$

で与えられる。式 (3.53) は $\varphi_{0}{ }^{\prime}$ をえる式 (3.13) と 全く同一の式であり, 式 (3.21)，(3.43）を参照すれ ば, 応力とひずみ速度場の両者の特性方向が一致するこ とが証明される。式 (3.53) に式 (3.52) を代入すれ ば, 平面ひずみの場合の $\alpha$ を用いて,

$$
\sin \psi=\frac{2 \cos \alpha\left(3+\cos ^{2} \alpha\right)}{-3+11 \cos ^{2} \alpha}
$$

と記することもできる。

\section{4. 総括}

（1）土の降伏条件としては, 従来 (a) Mohr-Coulomb, (b) 挔張 Tresca, (c) 拡張 von Mises の 3 条 件が考えられていたが, 本論文は実験結果を検討し, 次 の新しい降伏条件式（簡単のため, 粘着力は無視してい る)

$$
\sqrt{2 J_{2}}-\sqrt{3} \sin \varphi_{0}\left(p+\frac{3}{4} \cdot \frac{J_{3}}{J_{2}}\right)=0
$$

を提案した。ここに， $p, J_{2}, J_{3}$ はそれぞれ式 (2.13)， (2.16)，(2.28）で定義される応力テンソル $\sigma$ の 3 個の 独立な不変量, $\varphi_{0}$ は材料固有の定数である。

（2）式 (4.1) は, 2次元の場合の拡張 von Mises
(これは Mohr-Coulomb とも一致する) の条件

$$
\sqrt{J_{2}}-p \sin \varphi_{0}=0
$$

のもつ幾何学的意味を考察し, 3 次元の場合に拡張した 式

$$
\sqrt{2 J_{2}}-\sqrt{3} p \sin \varphi_{0}=0
$$

を実験結果に合致するように, 3 次元特有の不変量 $J_{3}$ によってさらに修正したものである。

(3) 式 (4.1) によると, Mohr-Coulomb の条件に おける限界角 $\varphi_{0}{ }^{\prime}$ は中間主応力によって変化し, その影 響を示すパラメーター $\alpha$ (式 (3.6) で定義) により，

$$
\sin \varphi_{0}^{\prime}=\frac{\sqrt{3} \sin \varphi_{0}}{\sqrt{2\left(1+\frac{1}{3} \cos ^{2} \alpha\right)+\frac{\sqrt{3}}{6}} \cdot \frac{\cos \alpha \sin ^{2} \alpha}{1+\frac{1}{3} \cos ^{2} \alpha} \sin \varphi_{0}}
$$

と示される。特に, 軸対称応力 (通常の 3 軸試験) の場 合には ( $\alpha=0$ または $2 \pi て ゙) ，$

$$
\sin \varphi_{0}{ }^{\prime}=\frac{3}{2 \sqrt{2}} \sin \varphi_{0}
$$

となる。

（4）式 (4.1)の左辺を塑性ポテンシャルとして，ひ ずみ速度場 $D \varepsilon / D t$ を求めれば,

$$
\begin{aligned}
D \varepsilon= & {\left[-\frac{\sqrt{3}}{3} \sin \varphi_{0} I+\frac{1}{\sqrt{2 J_{2}}} \sigma_{D}+\frac{3}{4} \sqrt{3} \sin \varphi_{0} \frac{J_{3}}{J_{2}}\right.} \\
& \left.\left.\cdot\left\{\frac{1}{J_{2}} \sigma_{D}-\left(\sigma_{D}\right)_{D}\right)_{D}\right\}\right] D \lambda \ldots \ldots \ldots \ldots \ldots . . .(4.6)
\end{aligned}
$$

が得られる (添字 $D$ はテンソルの偏差部分を示す)。こ のひずみ速度場は応力と主軸を共有し, また体積変化 (膨張)

$$
-D e=\sqrt{3} \sin \varphi_{0} D \lambda \ldots
$$

を伴うが，これはダイレイタンシーとして知られている 現象を説明している。このひずみ速度場は降伏曲面に垂 直なベクトルとなるから, 最大塑性仕事の原理や解の唯 一性などが保証される。

（5）平面ひずみの状態は，前記のパラメータームが 


$$
\frac{2 \sqrt{6} \cos \alpha\left(1+\frac{1}{3} \cos ^{2} \alpha\right)^{\frac{3}{2}}}{-3+10 \cos ^{2} \alpha+\cos ^{4} \alpha}=\sin \varphi_{0} \cdots \cdots
$$

を満足する時に生じる。この場合, 特性方向（すべり線 の方向）は主軸 I と

$$
\theta= \pm\left(\frac{\pi}{4}-\frac{\varphi_{0}{ }^{\prime}}{2}\right)
$$

の角度をなし，応力もひずみ速度も同一の特性方向をも つことが証明される。式 (4.8) の $\propto$ を用いれば, この $\varphi_{0}^{\prime}$ は

$$
\sin \varphi_{0}^{\prime}=\frac{2 \cos \alpha\left(3+\cos ^{2} \alpha\right)}{-3+11 \cos ^{2} \alpha}
$$

で与えられる。

\section{5.あとがき}

本論文は，土の降伏条件について，2 次元の場合の類 推から出発し, 最近の中間主応力の影響を検討した実験 結果の傾向ともよく適合するような一つの新しい条件式 を提案し, これから求められるひずみ速度場について若 干の塑性論的考察を行なったものである。土の性質はき わめて複雑なものであり, その降伏条件や塑性理論も, 当然, 単純な理論のみから解明できるものとは思われな いが，ここに提案した条件式がどういう物理的意味をも つか, その妥当性や適用について, さらに検討をすすめ て行きたいと考えている。

本論文を草するに当たり，東北大学河上房義教授より 全般についてのご教示を頂き，また同柳沢栄司講師より 多くの有益な助言や資料の提供を頂いた。ここに, 厚く
感謝の意を表する次第である。

\section{参考 文 献}

1）例えば, 最上武雄 (編): 土質力学, 技報堂 (1969), 492 $-506,747-758$

2) Bishop, A.W. : The Strength of Soils as Engineering Materials, Geotech. 16, No. 2 (1966), 91-130

3) Roscoe, K.H., Schofield, A.N. and Thurairajah, A. : An Evaluation of Test Date for Selecting a Yield Criterion for Soils, Laboratory Shear Testing of Soils, ASTM, STP No. 361 (1963), 111-128

4) Drucker, D.C. and Prager, W. : Soil Mechanics and Plastic Analysis or Limit Design, Quart. Appl. Math. 10, No. 2 (1952), 157-165

5）山口柏樹 : 塑性流動における速度場の 理論, 土木学会論 文集第 63 号 (1959), 8-16

6) 星埜 和：土の力学における塑性の基本理論と三軸試験 への適用, 土木学会論文集第 21 号 (1954)

7) Kirkpatrick, W.H. : The Condition of Failure for Sands, Proc. 4 th. Int. Conf. SMFE 1 (1957), 172178

8) Wu, T.H., Loh, A.K. and Malvern, L.E. : Study of Failure Envelope of Soils, Proc. ASCE 89, No. SM 1 (1963), 145-181

9) Shibata, T. and Karube, D. : Influence of the Variation of the Intermediate Principal Stress on the Mechanical Properties of Normally Consolidated Clays. Proc. 6 th Int. Conf. SMFE 1 (1965), 359-363

10）佐武正雄: モールの円の拡張と降伏条件の幾何学的考察, 日本材料強度学会誌 6, No. 1 (1971), 18-31

11）例えば, 吉村慶丸：塑性力学, 応用力学講座 4-A, 共立 出版 (1957), 106-137

12) Davis, E.H. : Theories of Plasticity and the Failure of Soil Masses, Soil Mechnics Selected Topics (Editted by Lee I.K.), Butterworth London (1968), 341380

(1970.10.28 - 受付) 